\title{
Orostachys japonicus inhibits the expression of MMP-2 and MMP-9 mRNA and modulates the expression of iNOS and COX-2 genes in human PMA-differentiated THP-1 cells via inhibition of $\mathrm{NF}-\kappa \mathrm{B}$ and MAPK activation
}

\author{
YOUNG IL KIM ${ }^{1}$, SEUNG-WON PARK ${ }^{2}$, YEO-KWANG YOON ${ }^{3}$, \\ KYUNG-WOOK LEE ${ }^{3}$, JANG-HOON LEE ${ }^{3}$, HONG-JUNG WOO ${ }^{3}$ and YOUNGCHUL KIM ${ }^{3}$ \\ ${ }^{1}$ Medical Science Research Institute, Kyung Hee University Medical Center, Seoul 130-872; ${ }^{2}$ Department of \\ Biotechnology, Catholic University of Daegu, Daegu 712-702; ${ }^{3}$ Department of Internal Medicine, \\ College of Korean Medicine, Kyung Hee University, Seoul 130-872, Republic of Korea
}

Received May 28, 2014; Accepted February 19, 2015

DOI: $10.3892 / \mathrm{mmr} .2015 .3460$

\begin{abstract}
Orostachys japonicus has been used in traditional medicine as an anticancer agent. The present study aimed to investigate the mechanism by which $O$. japonicus extract affects the expression of matrix metalloproteinase (MMP)-2 and MMP-9, its association with the expression of the inducible nitric oxide synthase (iNOS) and cyclooxygenase-2 (COX-2) genes in phorbol myristate acetate-differentiated THP-1 human monocytic leukemia cells and how it mediates the nuclear factor (NF)- $\mathrm{\kappa B}$ and mitogen-activated protein kinase (MAPK) pathways. Cell proliferation was analyzed by MTT assay, mRNA expression was detected by quantitative polymerase chain reaction and protein expression was measured by western blot analysis. It was demonstrated that $O$. japonicus suppressed the mRNA expression of MMP-2 and MMP-9. In addition, $O$. japonicus was found to downregulate iNOS and COX-2 transcription and translocation. Furthermore, O. japonicus inhibited NF- $\kappa \mathrm{B}$ p65 activity as well as the phosphorylation of p38 MAPK, MAPK kinase (MEK) and extracellular signal regulated kinase (ERK). The present results suggested that $O$. japonicus inhibited not only MMP-2 and MMP-9 mRNA expression, but also iNOS and COX-2 gene expression, suppressed NF- $\kappa \mathrm{B}$ activation and reduced phosphorylation of p38 MAPK, MEK and ERK. The present results therefore indicated that $O$. japonicus was able to inhibit
\end{abstract}

Correspondence to: Professor Youngchul Kim, Department of Internal Medicine, College of Korean Medicine, Kyung Hee University, 23 Kyungheedae-ro, Dongdaemun-gu, Seoul 130-872, Republic of Korea

E-mail: yckim@khmc.or.kr

Key words: Orostachys japonicus, cyclooxygenase-2, nuclear factor- $\kappa \mathrm{B}$, inducible nitric oxide synthase, matrix metalloproteinase, mitogen-activated protein kinase the expression of MMP-2 and MMP-9 and suppress the transcription and translocation of iNOS and COX-2 by directly inhibiting the activation of NF- $\mathrm{KB}$ and the phosphorylation of the MAPK pathway in THP-1 cells.

\section{Introduction}

Orostachys japonicus is a perennial herb that is primarily ubiquitous in Korea, China and Japan. Dried whole plants of this species have previously been used as a Chinese medicinal therapy for the treatment of fever, hemostasis, hepatitis, arthritis, eczema and intoxication; in addition, $O$. japonicus has traditionally been used in folk medicine as an anticancer agent (1). However, the extract nature of its physiological activity and the signaling pathway involved remain to be elucidated.

Matrix metalloproteinases (MMPs) have an important involvement in numerous physiological processes, including wound healing, angiogenesis and tissue remodeling. An alteration in their expression has been associated with the development of severe pathological conditions (2). MMP expression is mediated pre- and post-transcription. Numerous extracellular factors, including cytokines, growth factors, cell contact with the extracellular matrix as well as inducers and inhibitors, have been suggested to be involved in regulating MMP expression in various types of tumor cells $(3,4)$. The gelatinases, MMP-2 and MMP-9, digest components of the connective tissue matrix and type IV collagen within the basement membrane (5). MMP expression is known to be mediated by numerous stimulatory factors, including cytokines, growth factors and chemical agents (6). Various types of human tumors were reported to be associated with upregulated MMP-2 and MMP-9 expression (7-9). In addition, several experimental and clinical studies have reported a significant correlation between the extent of tumor aggression and increased levels of MMP-2 and MMP-9 (10-13).

Cyclooxygenase-2 (COX-2) is rapidly induced by cytokines and tumor promoters (14). COX-2 is upregulated in the 
majority of human tumor cells (15) and may be downregulated by the antitumoral effects of nonsteroidal anti-inflammatory drugs. Nitric oxide (NO) was reported to promote cancer progression by regulating tumor angiogenesis (16); in vivo studies have demonstrated an interaction between NO synthase (NOS) and the COX-2 pathway in inflammation (17). The inducible NOS (iNOS) and COX-2 genes were found to be upregulated in human colorectal cancer $(18,19)$ and tumor-associated macrophages reportedly express iNOS and COX-2 in certain malignant, borderline and benign tumors (20). In addition, nuclear factor- $\mathrm{kB}(\mathrm{NF}-\mathrm{\kappa B})$ is involved in the regulation of iNOS and COX-2 expression at the gene transcriptional or translational levels (21). Numerous studies have indicated that MMP gene expression was regulated specifically by mitogen-activated protein kinases (MAPKs), a family of serine/threonine kinases including ERKs, JNK and p38 MAPK (22-24). The present study aimed to investigate the mechanism by which $O$. japonicus extract affects the expression of MMP-2 and MMP-9, its association with the expression of iNOS and COX-2 in phorbol myristate acetate (PMA)-differentiated THP-1 human monocytic leukemia cells and how it mediates the regulation of the NF- $\mathrm{KB}$ and MAPK pathways.

\section{Materials and methods}

Extraction of O. japonicus. A total of $20 \mathrm{~g}$ O. japonicus was extracted by overnight incubation at $60^{\circ} \mathrm{C}$ in $500 \mathrm{ml} 80 \%$ methanol. The solution was filtered through Whatman No. 1 filter paper (Whatman International Ltd., Maidstone, UK) and concentrated using a rotary evaporator (Rotavapor R-220; BÜCHI Labortechnik AG, Flawil, Switzerland). The concentrated extract was freeze-dried (FD-1; EYELA, Tokyo, Japan) and stored at $4^{\circ} \mathrm{C}$ in a vacuum container until further use.

Cell culture. THP-1 human monocytic leukemia cells were supplied by the Korean Cell Line Bank (Seoul, Korea). Cells were cultured in RPMI 1640 medium containing 10\% fetal bovine serum and antibiotics (all from Gibco-BRL, Grand Island, NY, USA). Cells were incubated at $37^{\circ} \mathrm{C}$ in a humidified atmosphere of $5 \% \mathrm{CO}_{2}$. THP-1 cells were treated with $100 \mathrm{nM}$ PMA (Sigma-Aldrich, St. Louis, MO, USA) for $72 \mathrm{~h}$ to induce differentiation of the cells into macrophages. Following differentiation, non-attached cells were removed by aspiration. The adherent macrophages were then washed three times with RPMI 1640 medium and incubated in cell culture medium at $37^{\circ} \mathrm{C}$.

Cell viability. Cell proliferation was measured with Cell Titer 96 Aqueous One solution (Promega, Madison, WI, USA). Cells were seeded at a density of $1 \times 10^{4}$ cells/well in 96-well plates and incubated with various concentrations $(0,5,10$ and $25 \mu \mathrm{g} / \mathrm{ml}$ ) of $O$. japonicus at $37^{\circ} \mathrm{C}$ for 24,48 and $72 \mathrm{~h}$, respectively. Cell viability was determined using a colorimetric assay with phenazine methosulfate/MTS solution. Absorbance was determined at $490 \mathrm{~nm}$, with background subtraction at $650 \mathrm{~nm}$ (Emax, Molecular Devices, Sunnyvale, CA, USA).

Treatment with O.japonicus. THP-1 cells were incubated for $24 \mathrm{~h}$ in serum-free medium with $O$. japonicus $(0,5,10$, and $25 \mu \mathrm{g} / \mathrm{ml})$.

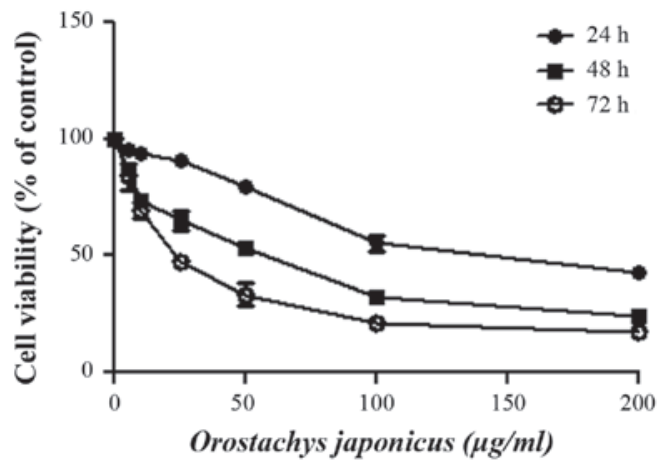

Figure 1. Orostachys japonicus extract inhibits proliferation of THP-1 cells. Cells were treated with various concentrations of $O$.japonicus $(0-500 \mu \mathrm{g} / \mathrm{ml})$ for 24, 48 and $72 \mathrm{~h}$. Cell viability was determined using the MTT assay. Values are expressed as the mean \pm standard deviation of triplicate samples.

At each time point, the cell culture supernatant, total RNA and total protein were isolated from the cultured THP-1 cells.

$R N A$ extraction and reverse transcription quantitative polymerase chain reaction $(R T-q P C R)$ procedures. Total RNA was purified from cultured cells using TRIzol reagent (Invitrogen Life Technologies, Carlsbad, CA, USA) according to the manufacturer's instructions. First-strand cDNA synthesis was performed with $1 \mu \mathrm{g}$ total RNA and transcribed to cDNA using a reverse-transcription system with random hexamers (A3500; Promega) according to the manufacturer's instructions. The sequences for gene-specific primers (Bioneer, Daejeon, Korea) were as follows: MMP-2 forward, 5'-CAACTACAACTTCTTCCCTCGCA-3' and reverse, 5'-GGTCACATCGCTCCAGACTTG-3' (141 bp); MMP-9 forward, 5'-GCATAAGGACGACGTGAATGGC-3' and reverse, 5'-CGGTGTGGTGGTGGTTGGAG-3' (83 bp); iNOS forward, 5'-TGGATGCAACCCCATTGTC-3' and reverse, 5'-CCCGCTGCCCCAGTTT-3' (59 bp); COX-2 forward, 5'-CAAATCCTTGCTGTTCCCACCCAT-3' and reverse, 5'-GTGCACTGTGTTTGGAGTGGGTTT-3' (173 bp); and $\beta$-actin forward, 5'-GCGAGAAGATGACCCAGATC-3' and reverse, 5'-GGATAGCACAGCCTGGATAG-3' (77 bp). qPCR was performed on a StepOnePlus real-time PCR system with Power SYBR Green PCR Master Mix (Applied Biosystems, Foster City, CA, USA). PCR was performed with $1 \mu \mathrm{l}$ cDNA in 20- $\mu 1$ reaction mixtures that were comprised of $10 \mu 1$ Power SYBR Green PCR Master Mix, $2 \mu 1$ primers and $7 \mu 1$ PCR-grade water (in A3500 reverse transcription system). The reactions were performed with a denaturation step at $95^{\circ} \mathrm{C}$ for $10 \mathrm{~min}, 40$ cycles of $95^{\circ} \mathrm{C}$ for $15 \mathrm{sec}$ and $60^{\circ} \mathrm{C}$ for $1 \mathrm{~min}$. The crossing point of the target genes with $\beta$-actin was calculated using the formula $2^{\text {-(target gene- } \beta \text {-actin) }}$ and the relative amounts were quantified.

Western blot analysis. The cells were collected and washed with cold phosphate-buffered saline (Welgene, Daegu, Korea) and lysed using lysis buffer [20 mM Tris- $\mathrm{HCl}$ (pH 7.5), $150 \mathrm{mM} \mathrm{NaCl}, 1 \mathrm{mM} \mathrm{Na}{ }_{2}$ EDTA, $1 \mathrm{mM}$ ethylene glycol tetraacetic acid, $1 \%$ Triton, $2.5 \mathrm{mM}$ sodium pyrophosphate, $1 \mathrm{mM} \beta$-glycerophosphate, $1 \mathrm{mM} \mathrm{Na}_{3} \mathrm{VO}_{4}$ and $1 \mu \mathrm{g} / \mathrm{ml}$ leupeptin] containing $1 \mathrm{mM}$ phenylmethylsulfonyl fluoride (Cell Signaling Technology, Boston, MA, USA). 

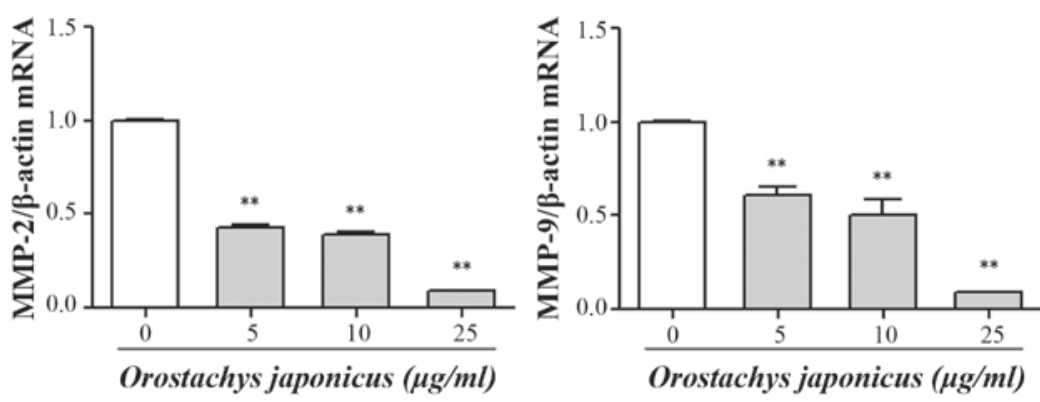

Figure 2. Orostachys japonicus inhibits mRNA expression of MMP-2 and MMP-9 in THP-1 cells. Cells were cultured with different concentrations of O.japonicus $(0,5,10$ and $25 \mu \mathrm{g} / \mathrm{ml})$ for $24 \mathrm{~h}$. mRNA levels were determined using reverse transcription quantitative polymerase chain reaction. The crossing points of target genes with $\beta$-actin were applied to the formula $2^{\text {-(target gene- } \beta \text {-actin) }}$ and the relative amounts were quantified. Values are expressed as the mean \pm standard deviation of three independent samples. ${ }^{* *} \mathrm{P}<0.01 \mathrm{vs} .0 \mu \mathrm{g} / \mathrm{ml}$ O. japonicus (control). MMP, matrix metalloproteinase.

The protein concentration was determined using a bicinchoninic acid protein assay (\#23227; Thermo Fisher Scientific, Rockford, IL, USA) according to the manufacturer's instructions. A total of $30 \mu \mathrm{g}$ protein (per group) was fractionated by $12 \%$ SDS-PAGE and transferred by electrophoresis onto nitrocellulose membranes. The membranes were blocked with $5 \%$ nonfat dry milk for $1 \mathrm{~h}$ at room temperature then incubated overnight at $4^{\circ} \mathrm{C}$ with antibodies against iNOS (AB5382; Chemicon, Billerica, MA, USA), COX-2 (SC-19999; Santa Cruz Biotechnology, Inc., Santa Cruz, CA, USA),

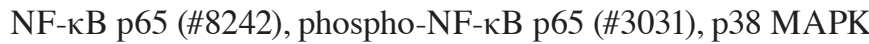
(\#9228), phospho-p38 MAPK (\#9215), MAPK kinase (MEK; \#4694), phospho-MEK (\#9154), ERK (\#4696), phospho-ERK (\#4376) (Cell Signaling Technology) and $\beta$-actin (A5441; Sigma-Aldrich); diluted 1:1,000 with Tris-buffered saline containing $0.05 \%$ Tween 20 (TBS-T). Following washing with TBS-T for $1 \mathrm{~h}$, the membranes were incubated for $1 \mathrm{~h}$ at room temperature with anti-rabbit (\#7074) and anti-mouse (\#7076) horseradish peroxidase-conjugated secondary antibodies diluted 1:2,500 in TBS-T. The membranes were subsequently washed with TBS-T for $1 \mathrm{~h}$ and proteins were detected using an enhanced chemiluminescence kit (Santa Cruz Biotechnology, Inc.). The protein expression was analyzed using a Davinch-Chemi ${ }^{\mathrm{TM}}$ Chemiluminescence Imaging System (CAS-400 Chemi-DOC Image Analyzer; Davinch-K Co. Ltd., Seoul, Korea).

Statistical analysis. Values are expressed as the mean \pm standard deviation. Student's t-test was used to evaluate differences between the control and O.japonicus-treated samples. ${ }^{*} \mathrm{P}<0.05$ and ${ }^{* *} \mathrm{P}<0.01$ were considered to indicate a statistically significant difference between values.

\section{Results}

Inhibition of cell viability by $O$. japonicus. The cytotoxic effect of $O$.japonicus on THP-1 cells was determined by exposing the cells to various concentrations of $O$. japonicus for 24, 48, and $72 \mathrm{~h}$. Cell viability was measured using the MTT assay. O. japonicus inhibited cell viability in THP-1 cells in a dose- and time-dependent manner (Fig. 1). However, $O$. japonicus had no effect on cell viability at a low concentrations; therefore, concentrations of 5,10 and $25 \mu \mathrm{g} / \mathrm{ml}$ were considered to be appropriate for the subsequent experiments.
Inhibition of MMP-2 and MMP-9 mRNA expression by $O$. japonicus. In order to investigate the effect of $O$.japonicus on the expression of MMP-2 and MMP-9, THP-1 cells were treated with various concentrations of $O$. japonicus $(0$, 5,10 , and $25 \mu \mathrm{g} / \mathrm{ml}$ ) for $24 \mathrm{~h}$. The expression of MMP mRNA was then determined using RT-qPCR. The results showed that treatment with $O$. japonicus led to a significant decrease in the MMP-2 and MMP-9 mRNA expression at each tested concentration compared with that of the control group $(\mathrm{P}<0.01)$ (Fig. 2).

Inhibition iNOS and COX-2 expression by O. japonicus. To examine the effects of $O$.japonicus on the expression of iNOS and COX-2 mRNA and protein, THP-1 cells were treated with various concentrations of $O$. japonicus $(5,10$ and $25 \mu \mathrm{g} / \mathrm{ml})$ for $24 \mathrm{~h}$. The expression of mRNA and protein were measured using RT-qPCR and western blot analysis. Treatment with O.japonicus significantly suppressed iNOS mRNA expression at all tested concentrations $(\mathrm{P}<0.01)$ and $\mathrm{iNOS}$ protein expression at 10 and $25 \mu \mathrm{g} / \mathrm{ml}$ O.japnicus $(\mathrm{P}<0.05$ and 0.01 , respectively) compared with that of the control. In addition, COX-2 transcription and translocation were significantly reduced at $25 \mu \mathrm{g} / \mathrm{ml} O$. japonicus compared with the control $(\mathrm{P}<0.01)$ (Fig. 3).

Inhibition of $\mathrm{NF}-\kappa \mathrm{B}$ p65 nuclear translocation by O. japonicus. In order to investigate the mechanisms involved in the inhibition of the NF- $\mathrm{NB}$ activity, THP-1 cells were treated with various concentrations of $O$. japonicus $(5,10$ and $25 \mu \mathrm{g} / \mathrm{ml})$ for $24 \mathrm{~h}$. The expression of NF- $\mathrm{kB}$ p 65 protein was determined by western blot analysis. The results showed that phosphorylation

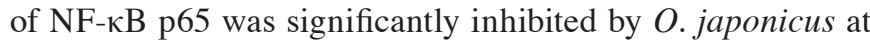
$25 \mu \mathrm{g} / \mathrm{ml}$ compared with the control (Fig. 4).

Inhibition of p38 MAPK, MEK and ERK phosphorylation by $O$.japonicus. The activation of signal transduction by $O$.japonicus was evaluated in THP-1 cells. The cells were treated with various concentrations of $O$. japonicus $(5,10$, and $25 \mu \mathrm{g} / \mathrm{ml})$ for $24 \mathrm{~h}$. The expression of p38 MAPK, MEK and ERK protein was then determined by western blot analysis. O. japonicus had no effects on total p38 MAPK and ERK expression compared with the control, whereas $O$. japonicus markedly suppressed their phosphorylation at concentrations of 10 and $25 \mu \mathrm{g} / \mathrm{ml}(\mathrm{P}<0.01)$ (Fig. 5). However, O. japonicus showed no significant affect on MEK phosphorylation. 

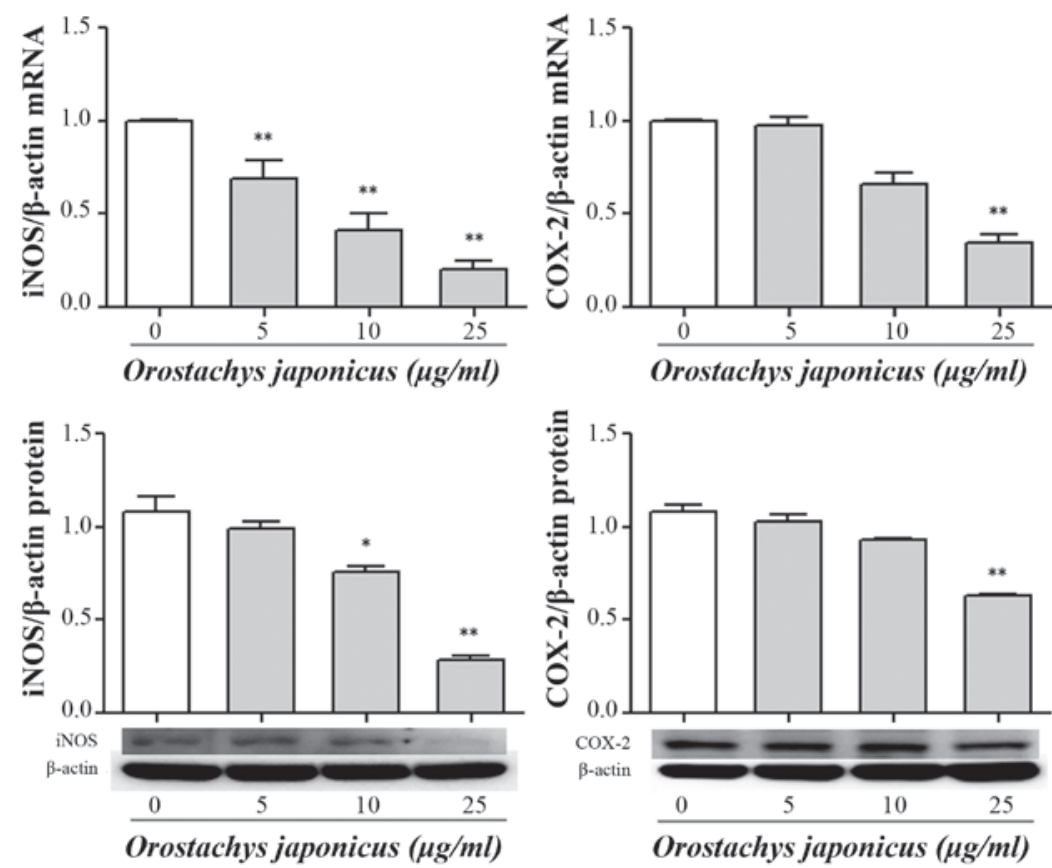

Figure 3. Orostachys japonicus inhibits the expression of iNOS and COX-2 genes in THP-1 cells. Cells were cultured with different concentrations of O. japonicus $(0,5,10$ and $25 \mu \mathrm{g} / \mathrm{ml})$ for $24 \mathrm{~h}$. mRNA levels were determined using reverse transcription quantitative polymerase chain reaction. The crossing points of target genes with $\beta$-actin were applied to the formula $2^{- \text {(target gene- } \beta \text {-actin) }}$ and relative amounts were quantified. Expression of iNOS and COX-2 protein was examined by immunoblotting. Densitometric analyses are presented as the relative ratios of iNOS and COX-2 against $\beta$-actin. Values are expressed as the mean \pm standard deviation of three independent samples. ${ }^{*} \mathrm{P}<0.05$ and ${ }^{* *} \mathrm{P}<0.01 \mathrm{vs} .0 \mu \mathrm{g} / \mathrm{ml} O$. japonicus (control). iNOS, inducible nitric oxide synthase; COX-2, cyclooxygenase-2.
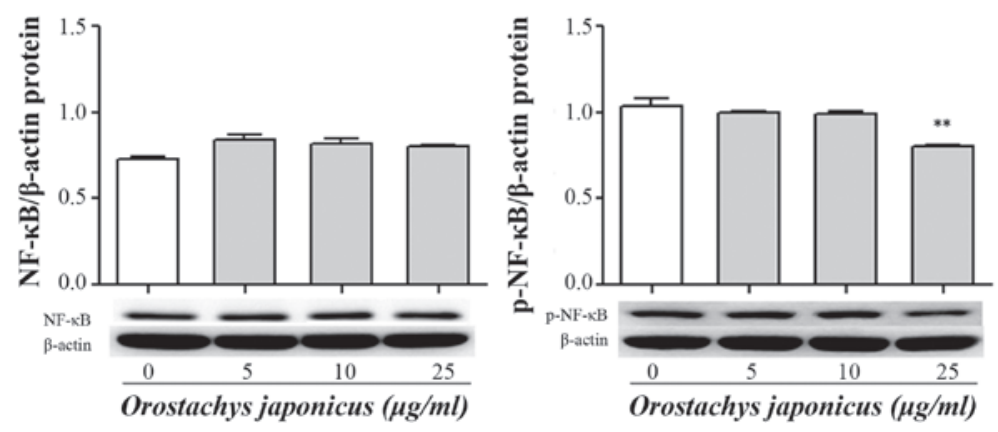

Figure 4. Orostachys japonicus inhibits NF-kB p65 activity in THP-1 cells. Cells were cultured with various concentrations of $O$. japonicus $(0,5,10$ and $25 \mu \mathrm{g} / \mathrm{ml}$ ) for $24 \mathrm{~h}$ and the expression of NF- $\mathrm{kB}$ p 65 protein was examined by immunoblotting. Densitometric analyses are presented as the relative ratios of

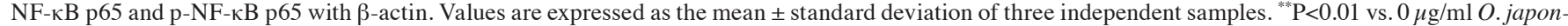
icus (control). NF, nuclear factor; p-, phosphorylated.

\section{Discussion}

In the present study, THP-1 human monocytic leukemia cells were induced to differentiate into macrophages using PMA and the cells were then treated with $O$. japonicus at various concentrations. It was identified that $O$. japonicus was able to inhibit cell proliferation in THP-1 cells in a time- and dose-dependent manner at a high concentration, whereas lower concentrations had no marked effect. Therefore, concentrations of 5,10 and $25 \mu \mathrm{g} / \mathrm{ml}$ were considered to be appropriate for the subsequent experiments.

In a previous study, the invasion and migration abilities of THP-1 human monocytic leukemia cells were significantly inhibited by Sinnomenine in a dose-dependent manner; in addition, the levels of MMP-2 and MMP-9 were downregulated (25). Another previous study demonstrated that the mRNA and protein expression of MMP-2 and MMP-9 in LnCaP prostate carcinoma cells were decreased following treatment with flavonoids extracted from O.japonicus (FEOJ) in a dose-dependent manner. These findings supported the idea that the suppression of MMPs by FEOJ is associated with the anti-invasive activity of FEOJ (26). It is possible that MMPs are not directly produced by cancer or stromal cells, but that other sites may be responsible for the increased levels of MMP-9, which were reported to correlate with the existence of tumor tissues (27). In the present study, it was demonstrated that $O$. japonicus inhibited MMP-2 and MMP-9 gene transcription. The present results suggested that $O$. japonicus inhibited migration and invasion of cancer cells by inhibiting the expression of MMP-2 and MMP-9 in THP-1 cells. 

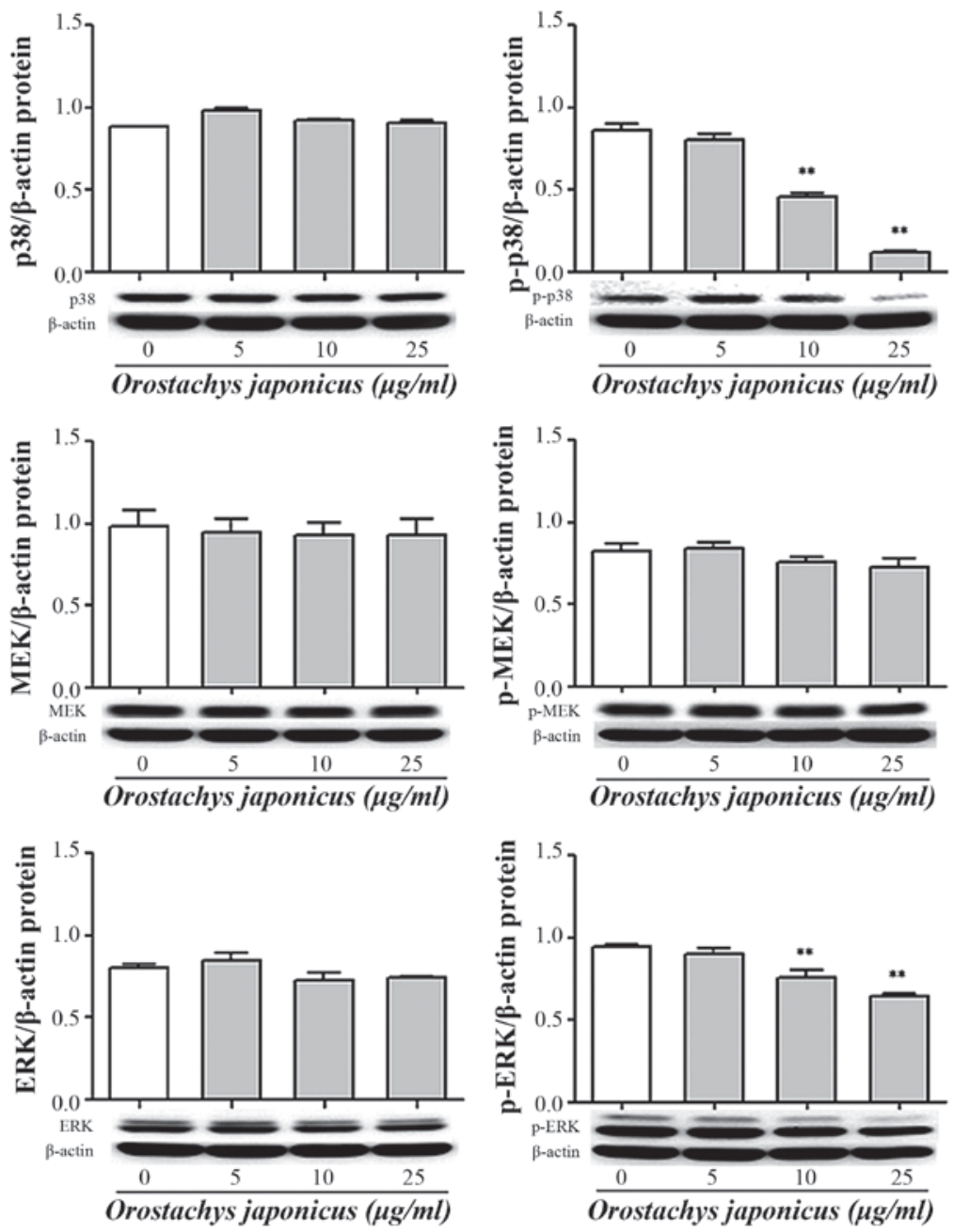

Figure 5. Orostachys japonicus inhibits p38 MAPK, MEK and ERK phosphorylation in THP-1 cells. Cells were cultured with various concentrations of O. japonicus $(0,5,10$ and $25 \mu \mathrm{g} / \mathrm{ml})$ for $24 \mathrm{~h}$ and the expression of p38 MAPK, MEK and ERK protein was examined by immunoblotting. Densitometric analyses are presented as the relative ratios of p38 MAPK, p-p38 MAPK, MEK, p-MEK, ERK_and p-ERK against $\beta$-actin. Values are expressed as the mean \pm standard deviation of three independent samples. ${ }^{* *} \mathrm{P}<0.01 \mathrm{vs} .0 \mu \mathrm{g} / \mathrm{ml}$ O. japonicus (control). MAPK, mitogen activated protein kinase; MEK, MAPK kinase; ERK, extracellular related kinase; p-, phosphorylated.

The NOS and COX systems are important in similar pathophysiological conditions, such as inflammation and cancer (28). In the present study, the effects of $O$. japonicus on $\mathrm{NO}$ were investigated and it was identified that $\mathrm{NO}$ was not detected in the culture supernatants of THP-1 cells. The present results revealed that $O$. japonicus inhibited iNOS and COX-2 mRNA and protein expression. Therefore, these findings suggested that $O$. japonicus mediated iNOS and COX-2 at the gene transcription and translocation levels in THP-1 cells. $\mathrm{NF}-\mathrm{KB}$ has been reported to mediate the expression of specific genes, the products of which were found to be involved in tumorigenesis. In addition, $\mathrm{NF}_{-} \mathrm{\kappa B}$ is able to induce the activation of MMP-9 and COX-2 $(29,30)$. Activation of NF- $\kappa$ B promotes proinflammatory cytokines and enzymes, including TNF- $\alpha$, interleukins, NO, prostaglandin $\mathrm{E}_{2}$, iNOS and COX-2, which may ultimately induce neuronal damage (31). In one study, treatment with shikonin was demonstrated to downregulate levels of MMP-2 and MMP-9 through the suppression of AKT activation as well as the inhibition of the NF- $\mathrm{KB}$ signaling pathway (32).

The MAPK cascade is an important signal transduction pathway. Members of the MAPK gene family, including
JNK, p38 MAPK and ERK1/2, enhance MMP production via activation of the transcription factor activation protein (AP-1) $(33,34)$. Silibinin reportedly reduces ERK1/2 phosphorylation, but has no observable effects on the phosphorylation of JNK 1/2, p38 MAPK or Akt (23). Expression of iNOS and COX-2 is upregulated by activated MAPKs with induction of the transcription factor AP-1 (35). ERK and p38 MAPK pathway suppression was reported to result in MMP-2 and MMP-9 downregulation in U937 leukemia cells (36). The inhibitory mechanism of andrographolide may proceed via the inhibition of NF- $\mathrm{KB}$ activation and subsequent attenuation of MMP-9 expression (37). In the present study, the phosphorylation levels of p38 MAPK and ERK1/2 were inhibited by $O$. japonicus. This notable finding suggested that modulation of the expression of the MMPs and inflammatory genes (COX-2 and iNOS) in THP-1 cells treated with O. japonicus was likely to be mediated by MAPKs, including p38 MAPK, MEK and ERK1/2.

In conclusion, O.japonicus treatment of PMA-differentiated THP-1 cells inhibited not only MMP-2 and MMP-9, but also iNOS and COX-2 transcription and translocation. The activation of NF- $\mathrm{kB}$ and the phosphorylation of p38 MAPK, 
MEK and ERK1/2 were also found to be reduced. However, $O$. japonicus may also inhibit the expression of MMP-2 and MMP-9 mRNA and the transcription and translation of iNOS and COX-2 by inhibiting the activation of NF- $\mathrm{kB}$ and phosphorylation of the MAPK pathway in THP-1 cells.

\section{References}

1. Kim JK (ed): Illustrated Natural Drugs Encyclopedia. Vol 1. $1^{\text {st }}$ Edition. Namsandang Press, Korea, pp14-167, 1984.

2. Visse R and Nagase H: Matrix metalloproteinases and tissue inhibitors of metalloproteinases: structure, function and biochemistry. Circ Res 92: 827-839, 2003.

3. Apodaca G, Rutka JT, Bouhana K, et al: Expression of metalloproteinases and metalloproteinase inhibitors by fetal astrocytes and glioma cells. Cancer Res 50: 2322-2329, 1990.

4. Ray JM and Stetler-Stevenson WG: The role of matrix metalloproteases and their inhibitors in tumour invasion, metastasis and angiogenesis. Eur Respir J 7: 2062-2072, 1994.

5. Stetler-Stevenson WG: Type IV collagenases in tumor invasion and metastasis. Cancer Metastasis Rev 9: 289-303, 1990.

6. Mauviel A: Cytokine regulation of metalloproteinase gene expression. J Cell Biochem 53: 288-295, 1993.

7. Di Nezza LA, Misajon A, Zhang J, et al: Presence of active gelatinases in endometrial carcinoma and correlation of matrix metalloproteinase expression with increasing tumor grade and invasion. Cancer 94: 1466-1475, 2002.

8. Sato T, Sakai T, Noguchi Y, Takita M, Hirakawa S and Ito A: Tumor-stromal cell contact promotes invasion of human uterine cervical carcinoma cells by augmenting the expression and activation of stromal matrix metalloproteinases. Gynecol Oncol 92 47-56, 2004.

9. Berube M, Deschambeault A, Boucher M, Germain L, Petitclerc E and Guerin SL: MMP-2 expression in uveal melanoma: differential activation status dictated by the cellular environment. Mol Vis 11: 1101-1111, 2005.

10. Cottam DW, Rennie IG, Woods K, Parsons MA, Bunning RA and Rees RC: Gelatinolytic metalloproteinase secretion patterns in ocular melanoma. Invest Ophthalmol Vis Sci 33: 1923-1927, 1992.

11. Garzetti GG, Ciavattini A, Lucarini G, et al: Tissue and serum metalloproteinase (MMP-2) expression in advanced ovarian serous cystoadenocarcinomas: clinical and prognostic implications. Anticancer Res 15 (6B): 2799-2804, 1995.

12. Fishman DA, Bafetti LM, Banionis S, Kearns AS, Chilukuri K and Stack MS: Production of extracellular matrix-degrading proteinases by primary cultures of human epithelial ovarian carcinoma cells. Cancer 80: 1457-1463, 1997.

13. Stetler-Stevenson WG: The role of matrix metalloproteinases in tumor invasion, metastasis and angiogenesis. Surg Oncol Clin N Am 10: 383-392, 2001.

14. Smith WL and Langenbach R: Why there are two cyclooxygenase isozymes. J Clin Invest 107: 1491-1495, 2001.

15. Koki AT, Leahy KM, Harmon JM and Masferrer JL: Cyclooxygenase-2 and cancer. In: COX-2 blockade in cancer prevention and therapy. Harris RE (ed). Humana Press, Totowa, NJ, pp185-203, 2003.

16. Gallo O, Fabbroni V, Sardi I, Magnelli L, Boddi V and Franchi A: Correlation between nitric oxide and cyclooxygenase- 2 pathways in head and neck squamous cell carcinomas. Biochem Biophys Res Commun 299: 517-524, 2002.

17. Han M, Wen JK, Zheng B and Zhang DQ: Acetylbritannilatone suppresses $\mathrm{NO}$ and $\mathrm{PGE}_{2}$ synthesis in RAW 264.7 macrophages through the inhibition of iNOS and COX-2 gene expression. Life Sci 75: 675-684, 2004.

18. Cianchi F, Cortesini C, Bechi P, et al: Up-regulation of cyclooxygenase 2 gene expression correlates with tumor angiogenesis in human colorectal cancer. Gastroenterology 121: 1339-1347, 2001.
19. Cianchi F, Cortesini C, Fantappie O, et al: Inducible nitric oxide synthase expression in human colorectal cancer: correlation with tumor angiogenesis. Am J Pathol 162: 793-801, 2003.

20. Klimp AH, Hollema H, Kempinga C, van der Zee AG, de Vries EG and Daemen T: Expression of cyclooxygenase-2 and inducible nitric oxide synthase in human ovarian tumors and tumor-associated macrophages. Cancer Res 61: 7305-7309, 2001.

21. Chiang YM, Lo CP, Chen YP, et al: Ethyl caffeate suppresses $\mathrm{NF}-\kappa \mathrm{B}$ activation and its downstream inflammatory mediators, iNOS, COX-2 and $\mathrm{PGE}_{2}$ in vitro or in mouse skin. Br J Pharmacol 146: 352-363, 2005.

22. Chen PN, Hsieh YS, Chiang CL, Chiou HL, Yang SF and Chu SC: Silibinin inhibits invasion of oral cancer cells by suppressing the MAPK pathway. J Dent Res 85: 220-225, 2006.

23. Hsieh YS, Chu SC, Yang SF, Chen PN, Liu YC and Lu KH: Silibinin suppresses human osteosarcoma MG-63 cell invasion by inhibiting the ERK-dependent c-Jun/AP-1 induction of MMP-2. Carcinogenesis 28: 977-987, 2007.

24. Weng CJ, Chau CF, Hsieh YS, Yang SF and Yen GC: Lucidenic acid inhibits PMA-induced invasion of human hepatoma cells through inactivating MAPK/ERK signal transduction pathway and reducing binding activities of NF- $\mathrm{KB}$ and AP-1. Carcinogenesis 29: 147-156, 2008

25. Ou YQ, Chen LH, Li XJ, Lin ZB and Li WD: Sinomenine influences capacity for invasion and migration in activated human monocytic THP-1 cells by inhibiting the expression of MMP-2, MMP-9 and CD147. Acta Pharmacol Sin 30: 435-441, 2009.

26. Shin DY, Lee WS, Jung JH, et al: Flavonoids from Orostachys japonicus A. Berger inhibit the invasion of $\mathrm{LnCaP}$ prostate carcinoma cells by inactivating Akt and modulating tight junctions. Int J Mol Sci 14: 18407-18420, 2013.

27. Quaranta M, Daniele A, Coviello M, et al: MMP-2, MMP-9, VEGF and CA 15.3 in breast cancer. Anticancer Res 27 (5B): 3593-3600, 2007.

28. Ohshima H, Tazawa H, Sylla BS and Sawa T: Prevention of human cancer by modulation of chronic inflammatory processes. Mutat Res 591: 110-122, 2005.

29. Pahl HL: Activators and target genes of Rel/NF- $\mathrm{BB}$ transcription factors. Oncogene 18: 6853-6866, 1999.

30. Garg A and Aggarwal BB: Nuclear transcription factor- $\kappa \mathrm{B}$ as a target for cancer drug development. Leukemia 16: 1053-1068, 2002.

31. Bi X, Yan B, Fang S, et al: Quetiapine regulates neurogenesis in ischemic mice by inhibiting NF- $\mathrm{\kappa B}$ p65/p50 expression. Neurol Res 31: 159-166, 2009.

32. Wei PL, Tu CC, Chen $\mathrm{CH}$, et al: Shikonin suppresses the migratory ability of hepatocellular carcinoma cells. J Agric Food Chem 61: 8191-8197, 2013.

33. Kanangat S, Postlethwaite A, Hasty K, et al: Induction of multiple matrix metalloproteinases in human dermal and synovial fibroblasts by Staphylococcus aureus: implications in the pathogenesis of septic arthritis and other soft tissue infections. Arthritis Res Ther 8: R176, 2006.

34. Menke NB, Ward KR, Witten TM, Bonchev DG and Diegelmann RF: Impaired wound healing. Clin Dermatol 25: 19-25, 2007.

35. Kim JM, Jung HY, Lee JY, Youn J, Lee CH and Kim KH: Mitogen-activated proteinkinase and activatorprotein-1 dependent signals are essential for Bacteroides fragilis enterotoxin-induced enteritis. Eur J Immunol 35: 2648-2657, 2005.

36. Liu WH and Chang LS: Caffeine induces matrix metalloproteinase-2 (MMP-2) and MMP-9 down-regulation in human leukemia U937 cells via $\mathrm{Ca}^{2+} / \mathrm{ROS}$-mediated suppression of ERK/c-fos pathway and activation of p38 MAPK/c-jun pathway. J Cell Physiol 224: 775-785, 2010.

37. Lee WR, Chung CL, Hsiao CJ, et al: Suppression of matrix metalloproteinase-9 expression by andrographolide in human monocytic THP-1 cells via inhibition of NF- $\kappa$ B activation. Phytomedicine 19: 270-277, 2012. 